\title{
3D SURVEY AND AUGMENTED REALITY FOR CULTURAL HERITAGE. THE CASE STUDY OF AURELIAN WALL AT CASTRA PRAETORIA IN ROME.
}

\author{
M. Canciani ${ }^{\text {a }}$, E. Conigliaro ${ }^{\text {b }}$, M. Del Grasso ${ }^{\text {c }}$, P. Papalini $^{\text {d }}$, M. Saccone ${ }^{\text {a* }}$ \\ a Dipartimento di Architettura, Università degli Studi Roma Tre - (marco.canciani, mauro.saccone)@uniroma3.it \\ b elisa.conigliaro@tiscali.it \\ cdelgrasso.monica@gmail.com \\ d pa.papalini@gmail.com \\ Special Session, SpS1-CIPA
}

KEY WORDS: Close-range photogrammetry, Documentation of Cultural Heritage, Virtual Reconstruction, Augmented Reality.

\begin{abstract}
:
The development of close-range photogrammetry has produced a lot of new possibility to study cultural heritage. 3D data acquired with conventional and low cost cameras can be used to document, investigate the full appearance, materials and conservation status, to help the restoration process and identify intervention priorities. At the same time, with 3D survey a lot of three-dimensional data are collected and analyzed by researchers, but there are a very few possibility of 3D output. The augmented reality is one of this possible output with a very low cost technology but a very interesting result. Using simple mobile technology (for iPad and Android Tablets) and shareware software (in the case presented "Augment") it is possible to share and visualize a large number of 3D models with your own device. The case study presented is a part of an architecture graduate thesis, made in Rome at Department of Architecture of Roma Tre University. We have developed a photogrammetric survey to study the Aurelian Wall at Castra Praetoria in Rome. The surveys of 8000 square meters of surface have allowed to identify stratigraphy and construction phases of a complex portion of Aurelian Wall, specially about the Northern door of Castra. During this study, the data coming out of 3D survey (photogrammetric and topographic), are stored and used to create a reverse 3D model, or virtual reconstruction, of the Northern door of Castra. This virtual reconstruction shows the door in the Tiberian period, nowadays it's totally hidden by a curtain wall but, little and significative architectural details allow to know its original feature. The 3D model of the ancient walls has been mapped with the exact type of bricks and mortar, oriented and scaled according to the existing one to use augmented reality. Finally, two kind of application have been developed, one on site, were you can see superimposed the virtual reconstruction on the existing walls using the image recognition. On the other hand, to show the results also during the graduation day, the same application has been created in off-site condition using a poster.
\end{abstract}

\section{INTRODUCTION}

Our goal is to present a three step methodology that start (I) from 3D integrated survey, studies (II) one of the most important ancient city walls and share (III) results and virtual reconstruction using augmented reality.

\subsection{Background}

Unlike the other European capitals, Rome is the only city that still preserves - almost entirely - its ancient walls: the Aurelian Walls. The Aurelian Walls are the biggest Roman monument, built by the Emperor Aureliano between the 270 and 275 a.D. to defend the city against possible attacks of barbarians. The city wall is about $19 \mathrm{~km}$ long and marks the boundaries of what is today defined as the Rome historical center. In spite of their historical relevance, the Aurelian Walls have for long been overlooked and clear guidelines towards the management and conservation of the monument as a whole are still missing. In order to respond to this need, the Department of Architecture at the University of Roma Tre and the local authority for the protection of the Roman cultural heritage (Sovraintendenza Capitolina ai Beni Culturali) started in 2010 a collaboration aimed to develop an information platform where the following tools and materials would be made available: (I) a Virtual Museum of the Aurelian Walls; (II) a catalogue and inventory of the existing wide - but currently scattered - documentation on the monument; (III) a list of activities and methodologies for identifying the priority actions and for monitoring the conservation status of the Walls; (IV) a technical manual for the management of the monument; and, (V) tools for the implementation of augmented reality studies.

In the framework of this project, a number of thesis works have been developed over the past years. Thanks to those studies, valuable information and data have been collected for the different sectors of the Aurelian Walls. One of those is the sector of the Castro Praetorio (Figure 1), which marked the boundaries of the homonym ancient military encampment.

\subsection{The Aurelian Walls at the Castro Praetorio}

"Castra Praetoria" was the name given to the big military encampment built in Rome by the Emperor Tiberio between 21 and 23 a.D. and aimed to gather under a unique big area the numerous courts of the army of the Empire (the Praetorian Guard).

The Castra Praetoria encampment was located in the northeastern part of the City and covered a wide area of almost 17

\footnotetext{
* Corresponding author
} 
hectares (440x380 meters). It had the typical structure of any other Roman military camp, characterized by a rectangular shape with rounded angles to guarantee a better protection against enemy attacks. The walls of the camp were 3.30 meters high and 2.30 meters thick. A long walkway run over their whole perimeter, lying on the lodging of the soldiers hosted in the camp. During the centuries, the camp hosted till 16,000 soldiers. Internally, the camp was structured on two main orthogonal roads - the Cardo and the Decumano - which crossed in the center of the camp, where the building reserved to the Emperor (praetorium) was located. Four doors were located on the four walls of the camp; of those, only two - the northern one and the eastern one - are visible today.

Since their building, the walls of the Castra Praetoria have undergone several changes, mainly aimed to reinforce their structure and increased their height. Two main changes can, however, be identified in the history of this monument: the inclusion of its walls in the Aurelian city walls, and the demolition of part of its walls when the Castro Praetorio military camp was take apart.

The first event was dated 271-275 a.D, when Emperor Aureliano decided to include two of the four walls of the military camp in the new born Rome defence system. On that occasion, the Castra Praetoria walls were also fortified with several towers. The second event was dated 312 a.D., when the Emperor Costantino demolished the western wall of the camp to put an end to the military body there hosted and avoid that the camp could be raised again. From then on, the area stopped being a military encampment.

No information on the use of the area is available from this last event up to the XVI century. The first reliable information comes from some documents from the XVI century, which describe the area as a big vineyard. In ... the area is documented as being of property of the Jesuit Order, which made it one of the most fruitful vineyard of Rome. In those years the area of the Castra Praetoria began to be called Macao, from the name of the Chinese city where the Order had one of the most successful missions. In 1860, when the Pope Pio IX decided to create his army to make the Papal State free in his defence, the southwestern part of the area was built up to host the Zuavi Pontifici (military barracks of Pio IX). In the 1870 - year of the unification of Italy - the barracks of Pio IX passed to the Italian Army.

In those years, new buildings were erected in the area and the previous vineyard completely disappeared.

When between the end of the XIX and the beginning of the XX century Rome started expanding beyond the city walls, some sectors of the ancient city walls started to be demolished. Among those, part of the northern wall of the Castra Praetoria sector, demolished to connect two major streets. This demolition definitively separated the area of the ancient military camp from the Aurelian walls system.

The area of the old Castra Pretoria remained of exclusive propriety of the Italian army until 1975, when the National Central Library of Rome was built.

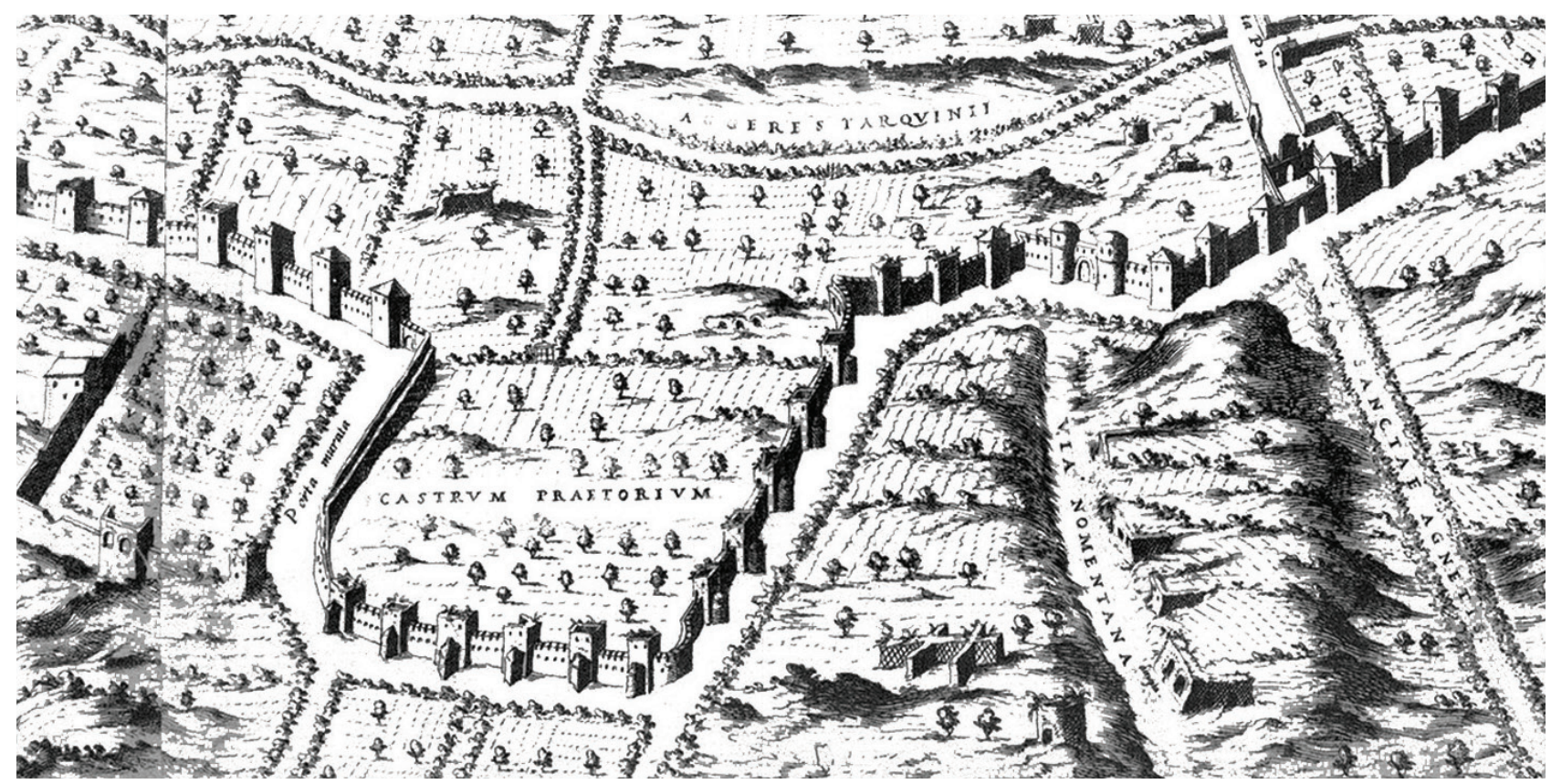

Figure 1. Ė. Du Perac, Nova Urbis Romae Descriptio, 1577. The Castro Pretorio area is abandoned, the wall was surrounded to Aurelian towers. 


\section{RELATED WORKS}

\subsection{D survey}

Working in archaeological areas requires knowledge in instruments and techniques for 3D survey well known and published in scientific literatures (Russo et al, 2011; Guidi 2009). In this case we have used the so called Integrated Survey (Maestri, 2007) an integration of (I) direct survey, only for some architectural details or bricks modules, (II) passive techniques (image based) and (III) active sensors (Trimble total station) to control and compare (Grussenmeyer, 2008) results and deformations. To control accuracy, as detailed below, we have planned a camera network with normal and convergent images (Remondino, 2014). As known there are some specific issues in surveying archaeological areas (Remondino, 2013), the Structure For Motion (SFM) techniques used in this project is fully automated and this create some problems with the accuracy. Our solution to reduce errors is (I) to plan the camera network as best as possible, (I) make different set of photos to test errors with Control Points (CPs), and especially with this kind of objects, a wall that is about 750 meters long, (III) we have created several $3 \mathrm{~d}$ models, split into different pieces to use a higher number of images for each pieces.

\subsection{Augmented Reality}

Augmented Reality (AR) as defined at Oxford dictionary is a technology that superimposes a computer-generated image (or model in our case) on a user's view of the real world, thus providing a composite view. The long story of mobile AR started in 1968 (Arth, 2015) and in the last few years has a big develop for the diffusion of smartphones and tablets. Since 2001 AR is used for cultural heritage (Vlahakis, 2001) and more recently we have application for tourism (Kounavis, 2012) and valorisation (Martínez, 2015; Villarejo, 2014). Last but not least is very interesting that several net economy companies are developing technology for mobile AR (Google with Google Glass; Microsoft with Holo Lens; ecc.) and this suggest that in next future AR will be used in daily. Several recent study create dedicated AR application for smartphone and tablets (Battini, 2015; Simonetto, 2013) using software like Unity or Vuforia. With this kind of application, you have to create (and download) your own app for each archaeological site, our goal is to use a software that easily can host different 3D models, linked to image or tracker, in only one application. We had chosen Augment (www.augmentedev.com) that easily dialog with 3D models come out from SFM procedures.

\section{3D SURVEY}

\subsection{Integrated survey}

The survey of the Castra Praetoria's walls concerned the northern sides (about 300 meters long) and the eastern side (about 450 meters long), for a total of 750 linear meters and more than 8000 square meters. Along this part of wall there are 20 towers - from D6 to D26 tower - that have been studied and analysed.

Several types of survey (topographic, photogrammetric and so called direct) have been utilized to get a wide but also detailed survey. This method, the so called Integrated Survey, is useful to control accuracy and quality specially when the survey area is large and complex like this.

\subsection{Topographic Survey}

First of all, we achieved the topographic survey with the Trimble Total Station. From a network of 9 control stations we have obtained the $650 \mathrm{CPs}$ to scale, rotate and translate the photogrammetric model. To create this network of CPs we have identify on façade many "marker", using architectural elements. For each part of the façade we have identified 9 CPs well dislocated to verify the accuracy of the model.



Figure 2. Topographic and Photogrammetric survey: portion of 3D model.

The triangulated surface with topographic control points and colour information. 


\subsection{Photogrammetric survey}

In the second step we have made the photogrammetric survey, a camera network with normal and convergent images have been planned to raise up accuracy. The use of this important methodology has been the base to get a good photographic coverage to be used as a basis in the stratigraphic analysis of the elevations. The Castro Pretorio's walls can't be studied only with the traditional method because of their inaccessibility.

Both facade was divided in several sectors to achieve the photographic sets and single wall can't be take in a single shot because of their dimension.

So we have realized 72 photo sets and more than 1.500 photos, with a calibrated Nikon digital camera (Nikon D3000 10,2 Megapixels). Of course the number of the sets was determined also by external factors such as the presence of a high-speed road, on the north side, and tall vegetation on the eastern side.

The photos were shot each day at the same time, in order to take the walls always in the same state of scattered light, avoiding strong contrasts and shadows of the vegetation. This is required to achieve the optimum illumination conditions necessary to the realization of valid textured surfaces for the stratigraphy and degradation analysis. The resolution of the photos (10 MP) influences the quality of the processing results so we have planned photo sets using the same distance for each image, an average distance from the wall of about $8 \mathrm{~m}$ each one.

Every single sector has been photographed by several angles, to produce normal and convergent images, to guarantee the successful completion of reconstruction task it is crucial the image overlap (75-80\%) across the input dataset.

Using a commercial software, Agisoft PhotoScan, we have processed individually each photo set to get a three-dimensional model. This model, consisting of triangulated mesh surfaces, is formed by a point cloud. Every single point of this cloud has already inside the corresponding colorimetric values.

Once obtained the three-dimensional model, we have imported the 650 CPs previously taken with the topographical instrument. Each point has been placed in the photographs of various sets, in this way we got 72 scaled and oriented models. Using a lot of CPs (Figure 2) we can estimate the quality of each model, and in some case we can re-process photo sets if the quality is not enough. The measures got with traditional methods, of some characteristic elements of the monument like bricks modules and so on, have allowed a direct comparison with the obtained model and even this kind of test has established its validity.

The 3D models allow to understand the trend of the surface and detecting the presence of out of plumb; it also provides the vertical sections of whole wall. The quality of the work achieved gave the possibility to have a graphic rendering 1:10 (Figure 3). The most significant elements of the Castra Praetoria's walls are the two remaining doors and the walkway between the towers D14 and D15. The frontal views of these elements, extrapolated from the $3 \mathrm{~d}$ model, formed the basis for all subsequent analysis as the stratigraphic analysis and the study of the evolutionary phases. To know the evolutionary phases of the masonry, the drawings obtained were compared with historical pictures (as the photos of the archaeologist J. H. Parker) and the literature (as the archaeologist L. Cozza).

The $3 \mathrm{~d}$ survey is useful for integrate the existing documentation on the monument. It is also helpful for monitoring the conservation status and for planning the priority interventions of the Castra Praetoria's walls.

\section{AUGMENTED REALITY}

The link between SFM process and AR is the use of 3D models to extract information and produce knowledge. All the SFM process produce sparse, dense cloud and finally a 3D mesh model with different kind of quality and texture. This $3 \mathrm{D}$ mesh models are usually studied, scaled, oriented, observed and sectioned to extract information and orthoimages.

In this case we have used the mesh model to create a virtual reconstruction of the Northern door of Castra using a mixed technique: (I) Data extracted (orthoimages and sections) have been studied to identify the different types of walls. (II) The

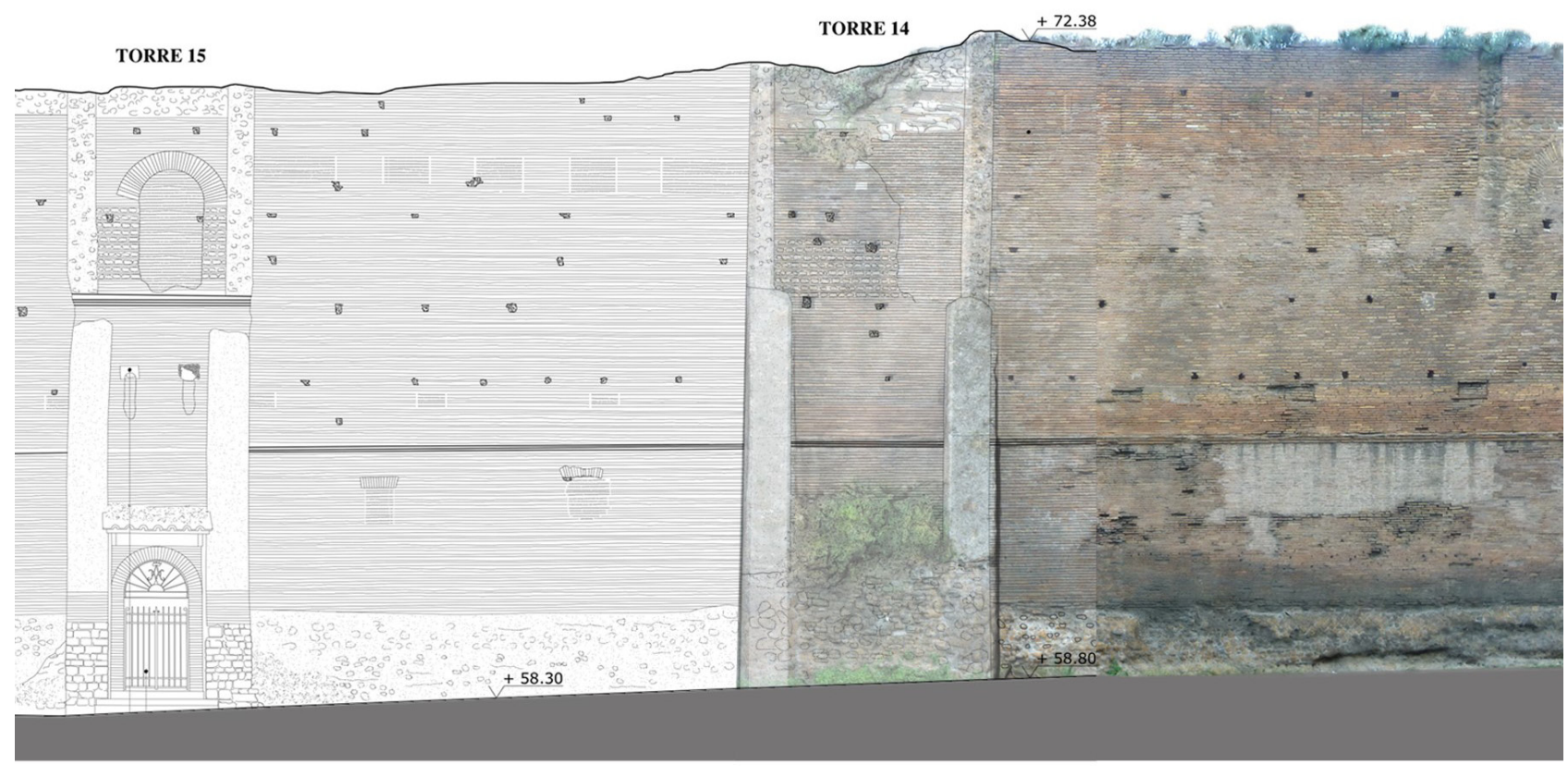

Figure 3. Front view, drawings and orthophoto. The 3D mesh model was used as base for the representation. 
mesh model was compared with different hypothesis of virtual reconstruction. (III) Finally a 3D geometric model was selected and it represent correctly the ancient aspect of the Northern door of Castra. (IV) Colour and texture have been moved from 3D mesh model to the geometric one.

This virtual reconstruction has been used for AR in two ways, on-site and off-site.

\subsection{Augmented on site.}

Nowadays only a few portion of the Northern door of Castra is visible, so we have to find a way to visualize his ancient aspect to visitors, tourists or technician. Using Augment application and website is possible to superimpose a 3D model on top of an image, called tracker. So the problem is how to superimposed the 3D models in its right position. We have created a dataset of photos tacked by different point of view (I), and with different light condition (II), using different mobile devices (III) smartphone and tablets. Each photo has to be uploaded in the Augment website to became a tracker, and for each photo you have to align $3 \mathrm{D}$ model and image. So as you can see in the figure (Figure 4) actually is possible to see the ancient Northern door of Castra directly on site. This kind of application have some limits. In fact, not all the positions are covered by dataset, we have chosen to prefer some points of view that are in front of the wall, at the other side of the road. We know that there are some useful software products that can recognize $3 \mathrm{D}$ objects or places to mix virtual models and reality (like Metaio, or some application of Vuforia) using algorithms for 3D recognition and tracking, but the aim of this project is to use only one App for different sites and different models and Augment seems to be the best one to reach this objective. The reason is that once fixed a pipeline to link 3D survey and $\mathrm{AR}$ we want to reproduce this project in other cases of studies like described below in "future works".

\subsection{Augmented off-site.}

If the virtual reconstruction on-site is useful to verify hypothesis and to make connection between 3D models and reality, the same application can be used out-site to disseminate knowledge and 3D data. Educational use of AR can take the same 3D models superimposed on posters that can explain more contents. In our case study the same model has been used to visualize the Northern door of Castra with a poster for the graduation thesis as you can see in figure (Figure 5).

\section{CONCLUSION AND FUTURE WORKS}

There is a couple of much more interesting use for AR. One of this, off-site, came from the link between SFM and AR. Each SFM process can create easily low detailed 3D mesh model that are very useful for AR. Using this kind of models, it is possible to show data came out from photogrammetric survey, mixed models with virtual reconstruction, or adding data analysis. Following this line our research group at Dipartimento di Architettura, University of Roma Tre, is working on AR project on-site and off-site to show the results of Virtual Reconstruction of Circo Massimo in Rome (Canciani, 2013).

On the other hand, when algorithms for $3 \mathrm{D}$ recognition and tracking will be much more efficient, AR can be used for documentation, monitoring and diagnostics for cultural heritage. Data (deterioration, diagnostics, restoration, historical information) can be visualize directly on-site, superimposed on the building to help conservators or archaeologists to improve knowledge (Figure 6).

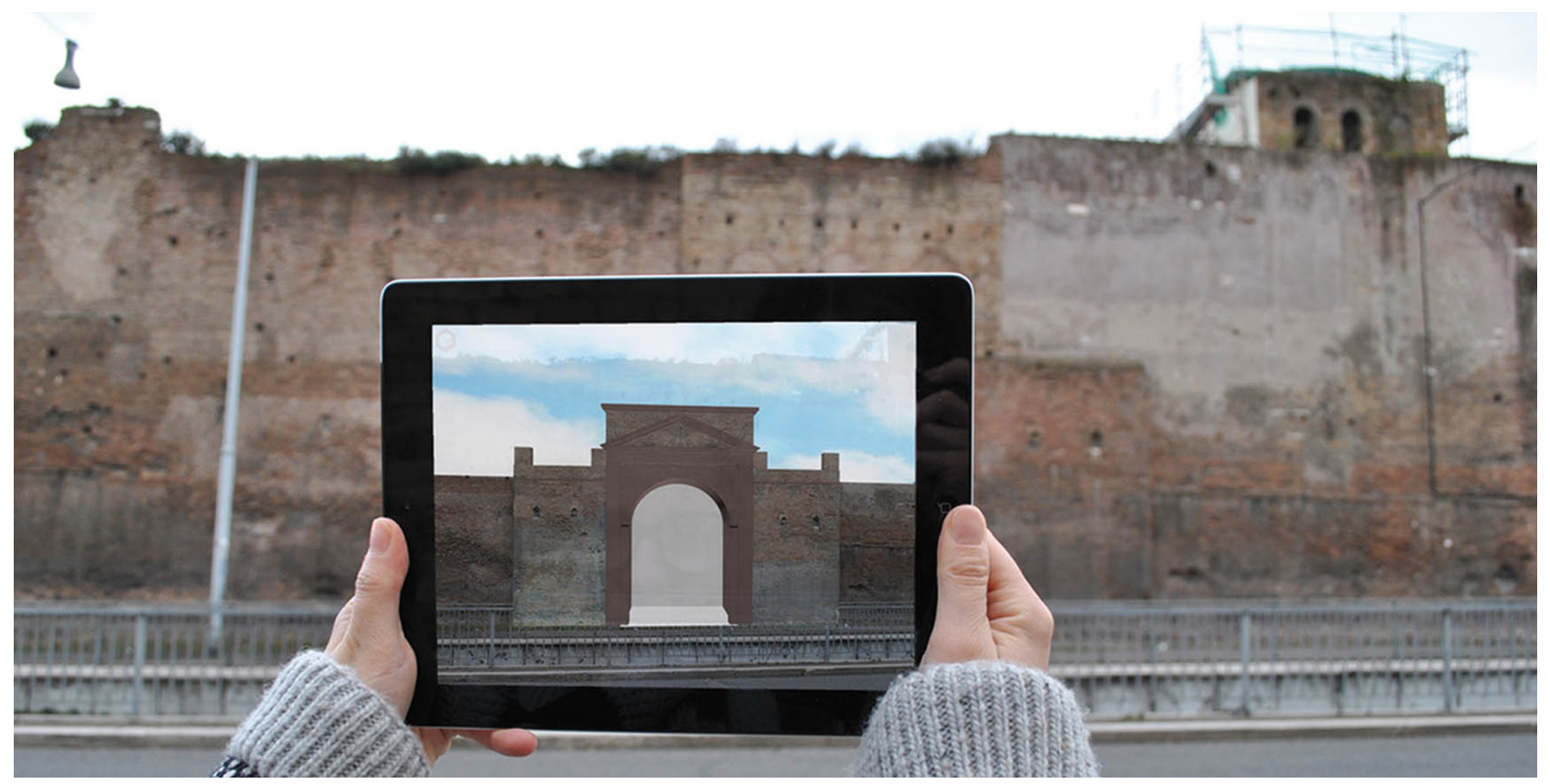

Figure 4. Augmented Reality On-site. 


\section{REFERENCES}

Arth, C., Grasset, R., Gruber, L., Langlotz, T., Mulloni, A., \& Wagner, D., 2015. The History of Mobile Augmented Reality. arXiv preprint arXiv:1505.01319.

Battini, C., Landi, G., 2015. 3D tracking based augmented reality for cultural heritage data management, Int. Arch. Photogramm. Remote Sens. Spatial Inf. Sci., XL-5/W4, 375$379,2015$.

Bonacini, E., 2014. La realtà aumentata e le app culturali in Italia: storie da un matrimonio in mobilità. In: Il Capitale Culturale. Studies on the Value of Cultural Heritage, (9), 89-121.

Canciani, M., Falcolini, C., Buonfiglio, M., Pergola, S., Saccone, M., Mammì, B., Romito, G., 2013. A method for virtual anastylosis: the case of the arch of Titus at the circus maximus in Rome, ISPRS Ann. Photogramm. Remote Sens. Spatial Inf. Sci., II-5/W1, 61-66, doi:10.5194/isprsannals-II-5-W1-61-2013.

Gonizzi Barsanti, S., Remondino, F., Visintini, D., 2013. 3d surveying and modeling of archaeological sites - Some critical issues -, ISPRS Ann. Photogramm. Remote Sens. Spatial Inf. Sci., II-5/W1, 145-150, doi:10.5194/isprsannals-II-5-W1-1452013.

Guarnieri, A., Remondino, F., Vettore, A., 2006. Digital photogrammetry and TLS data fusion applied to Cultural Heritage 3D modeling. The International Archives of Photogrammetry, Remote Sensing and Spatial Information Sciences, Vol. 36(5).

Kounavis, C. D., Kasimati, A. E., Zamani, E. D., \& Giaglis, G. M., 2012. Enhancing the tourism experience through mobile augmented reality: Challenges and prospects. International Journal of Engineering Business Management, 4(10), 1-6
Maestri, D., Canciani, M., Spadafora, G., 2007. The integrated survey for the knowledge and the documentation of the archaeological heritage: the "Villa dei Misteri" in Pompei. The Cipa International Archives for Documentation of Cultural Heritage, Volume XXI-2007.

Manferdini, A. M., \& Russo, M. ,2013. Multi-scalar 3D digitization of Cultural Heritage using a low-cost integrated approach. In Digital Heritage International Congress (DigitalHeritage), 2013 (Vol. 1, pp. 153-160). IEEE.

Martínez, J. L., Álvarez, S., Finat-Saez, J., Delgado, F. J., Finat, J., 2015. Augmented reality to preserve hidden vestiges in historical cities. a case study, Int. Arch. Photogramm. Remote Sens. Spatial Inf. Sci., XL-5/W4, 61-67, doi:10.5194/isprsarchives-XL-5-W4-61-2015.

Nocerino, E., Menna, F., and Remondino, F., 2014. Accuracy of typical photogrammetric networks in cultural heritage 3D modeling projects, Int. Arch. Photogramm. Remote Sens. Spatial Inf. Sci., XL-5, 465-472, doi:10.5194/isprsarchives-XL-5-4652014.

Ramos, M. M., Remondino, F., 2015. Data fusion in Cultural Heritage - A Review, Int. Arch. Photogramm. Remote Sens. Spatial Inf. Sci., XL-5/W7, 359-363, doi:10.5194/isprsarchivesXL-5-W7-359-2015, 2015.

Remondino, F., 2011. Rilievo e modellazione 3D di siti e architetture complesse. Disegnarecon, Università di Bologna, 4(8), pp. 90-98.

Russo, M., Remondino, F., Guidi, g., 2011. Principali tecniche e strumenti per il rilievo tridimensionale in ambito archeologico. Archeologia e Calcolatori, 22, 2011, pp. 169-198.

Serna, C. G., Pillay, R., \& Trémeau, A., 2015. Data Fusion of Objects Using Techniques Such as Laser Scanning, Structured

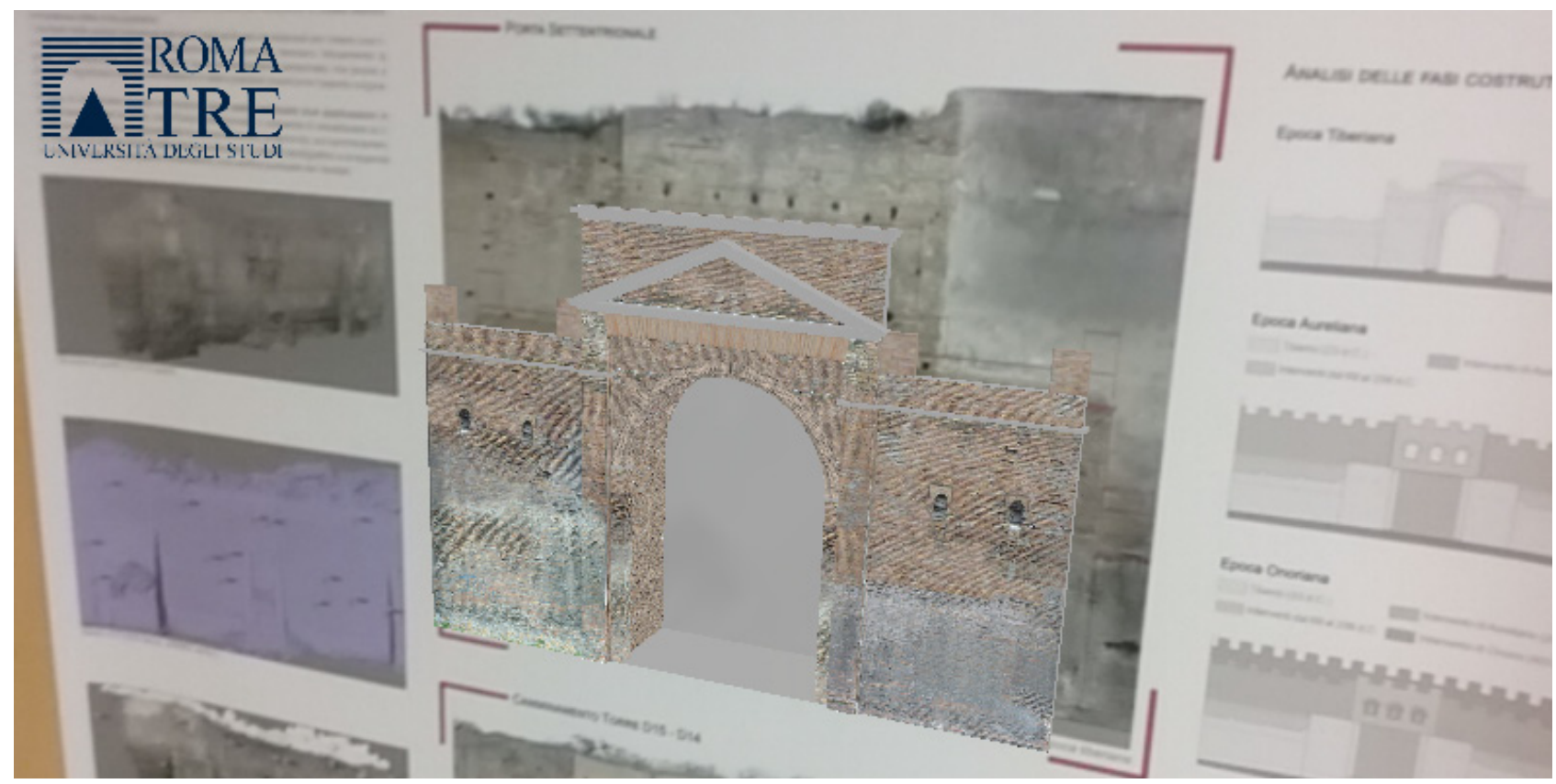

Figure 5. Augmented Reality Off-site, educational use. 
Light and Photogrammetry for Cultural Heritage Applications. Computational Color Imaging (pp. 208-224). Springer.

Simonetto, E., Froment, C., Labergerie, E., Ferré, G., Séchet, B., Chédorge, H., Cali, J., Polidori, L., 2013. Valorisation of cultural heritage through virtual visit and augmented reality: the case of the Abbey of Epau (France), ISPRS Ann. Photogramm. Remote Sens. Spatial Inf. Sci., II-5/W1, 289-294, doi:10.5194/isprsannals-II-5-W1-289-2013.

Villarejo, L., González, F., Miralbell, O. \& Gomis J.M, 2014. Introducing Augmented Reality in Cultural Heritage Studies. eLC Research Paper Series, 8, 06-14.

Vlahakis, V., Karigiannis, J., Tsotros, M., Gounaris, M., Almeida, L., Stricker, D., Gleue, T., Christou, I. T., Carlucci, R. Ioannidis, N., 2001. Archeoguide: First results of an augmented reality, mobile computing system in cultural heritage sites," in Proceedings of the 2001 Conference on Virtual Reality, Archeology, and Cultural Heritage, VAST '01, (New York, NY, USA), pp. 131\{140, ACM, 2001. 12, 13

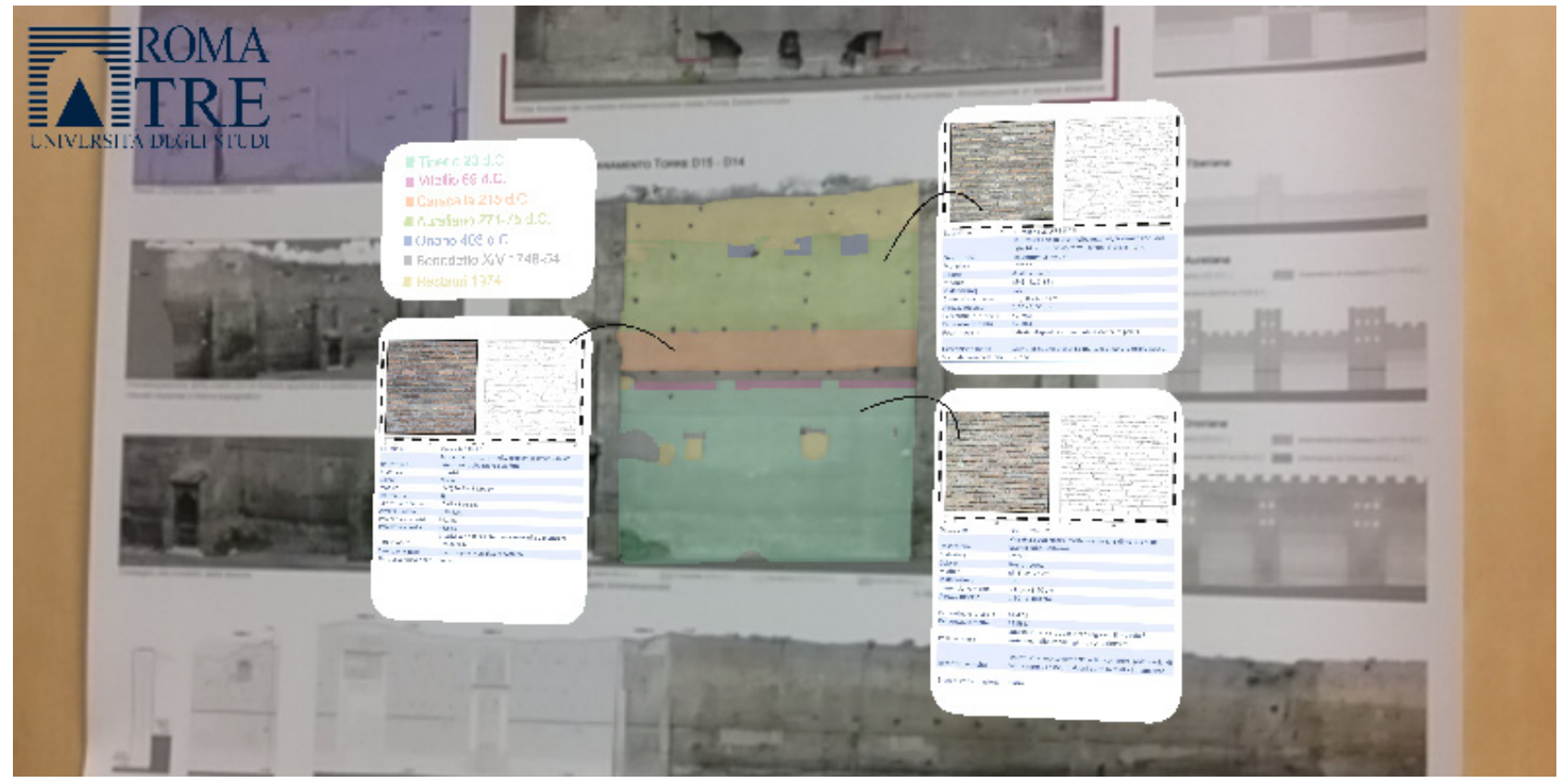

Figure 6. Augmented Reality can be used to store and visualize data like the different types of walls. 